\title{
A Patent Prize System to Promote development of NeW Antibiotics AND CONSERVATION OF EXISTING ONES
}

\author{
By Mark Nickas* \\ Volume XII - Spring 2012
}

\begin{abstract}
Antibiotics are valuable drugs that fight bacterial infections, but our supply of antibiotics is at risk. Existing antibiotics gradually lose their effectiveness due to bacterial resistance, and few new antibiotics are being developed to replace them. A variety of models have been proposed to promote the conservation of existing antibiotics or incentivize private actors, i.e., drug companies, to develop new ones. Previous models, however, all encourage investment in antibiotic research and development via patent rights, which also create an incentive to oversell antibiotics. Because the inappropriate use of antibiotics accelerates the development of resistance, patent rights put the public health objectives of antibiotic development and conservation in tension with one another. This article proposes an antibiotic-specific patent prize system that uncouples the two policy objectives necessary to achieve a stable antibiotic supply. Although others have proposed patent prize systems to promote drug development generally, the system described here is tailored to address the unique features of antibiotic markets.
\end{abstract}

* J.D. candidate, Boston University School of Law; Ph.D., University of California, San Diego; B.A. Northwestern University. I would like to thank Kevin Outterson for his encouragement, input, and guidance in writing this article. 


\title{
A Patent Prize System to Promote development of NeW Antibiotics AND CONSERVATION OF EXISTING ONES
}

\author{
By Mark Nickas*
}

Volume XII - Spring 2012

\section{Contents}

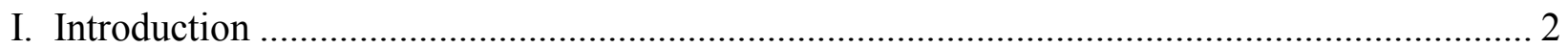

II. Existing Models to Promote Antibiotic Development and Conservation .................................. 3

A. Property-based Models ............................................................................................ 4

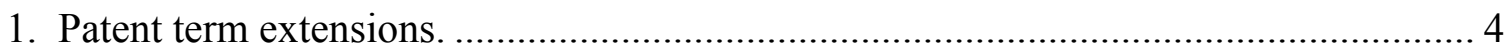

2. Government-based antibiotic development. ........................................................... 7

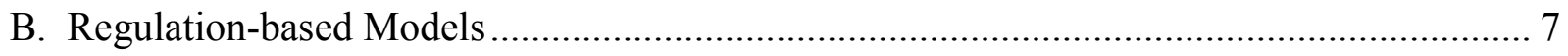

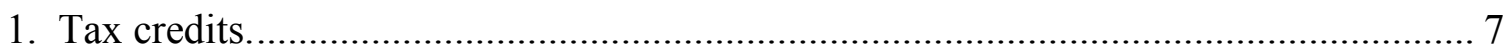

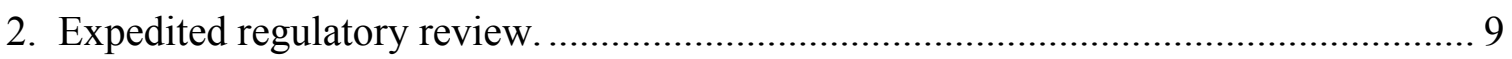

3. Changes in FDA approval guidelines................................................................ 10

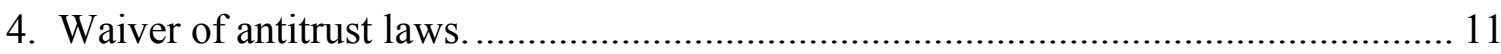

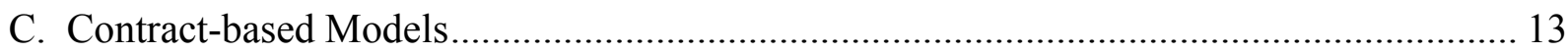

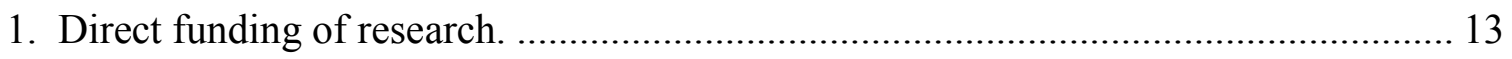

2. Advance purchase commitments ........................................................................ 14

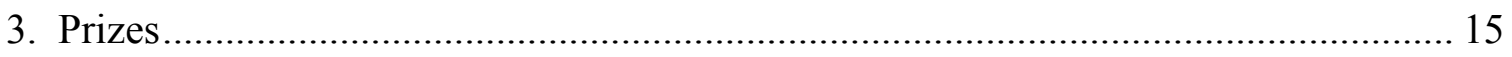

4. Publicly-sponsored early-stage research collaborations .............................................. 17

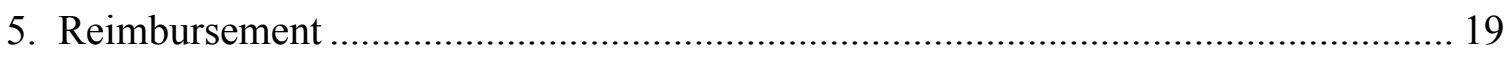

III. A New Model for Uncoupling Antibiotic Development from Sales (UADS)....................... 20

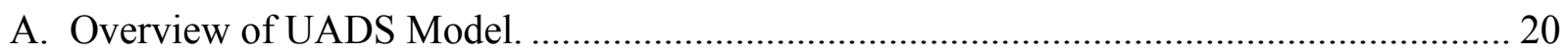

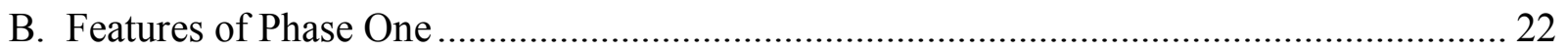

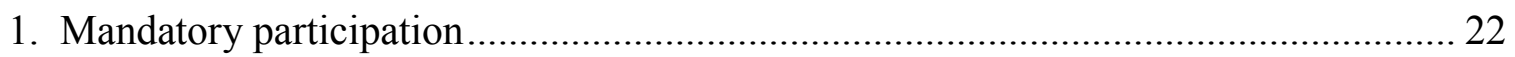

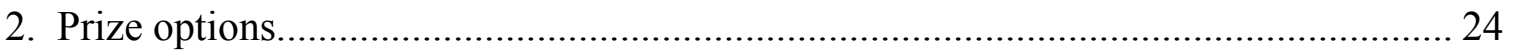

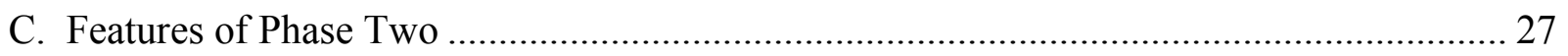

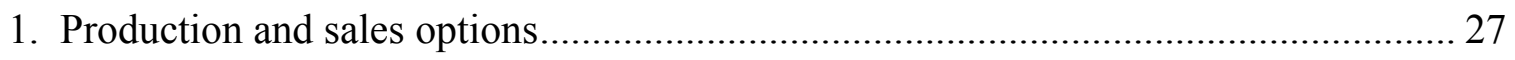

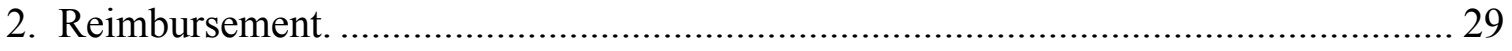

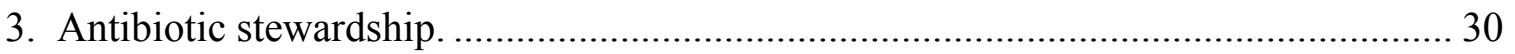

D. Supplemental Mechanisms Compatible with UADS Model ................................................ 33

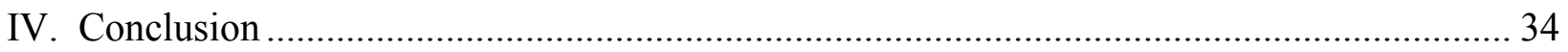

* J.D. candidate, Boston University School of Law; Ph.D., University of California, San Diego; B.A. Northwestern University. I would like to thank Kevin Outterson for his encouragement, input, and guidance in writing this article.

PGH. J. TECH. L. \& POL'Y, Vol. 12, No. 5, Spring 2012 


\section{Introduction}

The discovery of antibiotics in the middle part of the twentieth century revolutionized modern medicine. The medical use of antibiotics turned many bacterial infections from grave diagnoses into manageable conditions and made possible a variety of advanced interventions, such as surgery and cancer treatment. ${ }^{1}$ However, the use of an antibiotic to treat bacterial infections triggers a Darwinian selection among the microbial population for strains of the pathogen that are resistant to that antibiotic. ${ }^{2}$ Thus, as the use of the antibiotic increases, so does resistance to the antibiotic among the bacterial population, thereby undermining the effectiveness of the antibiotic. Consequently, prevention of human mortality and morbidity resulting from bacterial infections requires coordinated efforts aimed at three interdependent goals: development of new antibiotics, conservation of existing antibiotics, and control of infection outbreaks. $^{3}$

Pharmaceutical companies have veered away from development of new antibiotics over the last few decades because other drugs are more profitable for several reasons. ${ }^{4}$ According to one group of commentators, antibiotics do not give developers a favorable return on their investment because the health care market vastly undervalues this class of drugs. ${ }^{5}$ In addition, the availability of generic antibiotics that are still effective against many bacterial infections leads public health authorities to relegate new antibiotics to a second (or later) line of defense against these pathogens. ${ }^{6}$ The likelihood that new antibiotics will be prescribed sparingly during

\footnotetext{
${ }^{1}$ See Antibiotic Resistance: Promoting Critically Needed Antibiotic Research and Development and the Appropriate Use ("Stewardship") of these Precious Drugs: Hearing Before the House Comm. on Energy and Commerce Subcomm. on Health, 111th Cong. 4-6 (2010) [hereinafter Antibiotic Hearing] (statement of Brad Spellberg, Infectious Diseases Society of America).

${ }^{2}$ Marc Lipsitch, The Rise and Fall of Antimicrobial Resistance, 9 TRENDS In MicroBIOLOGY 438, 441-42 (2001).

${ }^{3}$ See Aaron S. Kesselheim \& Kevin Outterson, Improving Antibiotic Markets for Long-Term Sustainability, 11 YALE J. HeALTH PoL'Y L. \& ETHICS 101 (2011).

${ }^{4}$ Steven J. Projan, Why is big Pharma getting out of antibacterial drug discovery?, 6 CURRENT OPINION IN MicROBIOLOGY 427, 428 (2003).

${ }^{5}$ Kesselheim \& Outterson, supra note 4, at 150-53.

${ }^{6}$ Chantal Morel \& Elias Mossialos, Stoking the Antibiotic Pipeline, 340 BRIT. MED. J. 1115, 1115 (2010).
} 
their period of patent protection undermines the financial incentive for companies to develop them. ${ }^{7}$ Moreover, drug makers may fear that resistance will impair sales of a new antibiotic. ${ }^{8}$ Finally, the uncertainty of obtaining the U.S. Food and Drug Administration's (FDA) approval for a new antibiotic thwarts some pharmaceutical companies from entering the antibiotic field. ${ }^{9}$

Efforts to conserve antibiotic effectiveness and control outbreaks of infection face a different set of obstacles. First, measures that seek to limit the use of a particular antibiotic to medically necessary indications place the interests of public health squarely in opposition to those of drug manufacturers. ${ }^{10}$ Consequently, the pharmaceutical industry has vehemently fought formulary restrictions that would promote antibiotic conservation. ${ }^{11}$ A second incentive problem is that infection control measures, such as screening patients for infectious pathogens and isolating infected patients in special wards, may go unrewarded. ${ }^{12}$ Individual hospitals that implement such preventative measures can reduce their use of antibiotics but may not be reimbursed for these activities by insurance companies. ${ }^{13}$ In addition, the coordination of infection control programs between hospitals in a local area could also help prevent the spread of pathogens and dampen the use of antibiotics. ${ }^{14}$ However, there are also limited financial incentives for regional cooperation among health care institutions are lacking. ${ }^{15}$

\section{Existing Models to Promote Antibiotic Development and Conservation}

Within the last decade, several commentators have proposed a variety of models to

\footnotetext{
${ }^{7}$ Kevin Outterson et al., Will Longer Antimicrobial Patents Improve General Global Public Health?, 7 LANCET INFECTIOUS DiSEASES 559, 564 (2007); Brad Spellberg et al., The Epidemic of Antibiotic-Resistant Infections: A Call to Action for the Medical Community from the Infectious Diseases Society of America, 46 CLINICAL INFECTIOUS DISEASES 155, 158 (2008).

${ }^{8}$ Morel \& Mossialos, supra note 7 , at 1115.

${ }^{9} I d$. at 1116 .

${ }^{10}$ See Kesselheim \& Outterson, supra note 4, at 126.

${ }^{11} \mathrm{Id}$.

${ }^{12}$ See id. at 124-26.

${ }^{13} \mathrm{Id}$. at 126.

${ }^{14}$ Kevin Outterson, The Legal Ecology of Resistance: The Role of Antibiotic Resistance in Pharmaceutical Innovation, 31 CARDOZO L. REV. 613, 633 (2010).

${ }^{15}$ Kesselheim \& Outterson, supra note 4, at 127. 
address the potential antibiotic shortage. ${ }^{16}$ Analysts have used different schemes for classifying these proposals based on three key elements. The first element used for classification is the legal mechanism that the proposal seeks to employ. ${ }^{17}$ One group of commentators has identified four "primary legal tools" that most proposals use: property, regulation, contract, and tort. ${ }^{18}$ Another element that serves as a basis for classifying proposals to promote long-term antibiotic effectiveness is the intermediate policy goal of the proposal: antibiotic production or antibiotic conservation. ${ }^{19}$ The third element that analysts use to categorize antibiotic proposals is the type of incentive upon which the proposal relies: "push" or "pull." "[P] "[ush incentives pay for research inputs, funding or rewarding research and development $(\mathrm{R} \& \mathrm{D})$ effort ex ante, i.e. irrespective of the outcome, and pull incentives pay for research outputs, rewarding R\&D effort ex post, if the outputs of $\mathrm{R} \& \mathrm{D}$ result in a health gain." ${ }^{21}$ For organizational simplicity, these proposals are categorized here according to legal mechanism (element one), but other elements of the proposals, i.e., policy goals and types of incentive, are discussed as relevant. ${ }^{22}$

\section{A. PROPERTY-BASED MODELS}

\section{Patent term extensions.}

One property-based proposal to combat antibiotic shortage is to extend patent terms to give patent holders a longer period of exclusive rights. ${ }^{23}$ In its most basic form, a patent term extension (PTE) provides the holder of a patent for a new antibiotic with an additional period of

\footnotetext{
${ }^{16}$ See, e.g., Elias Mossialos et al., Policies and Incentives for Promoting Innovation in Antibiotic Research, EUROPEAN OBSERVATORY ON HEALTH SYSTEMS \& POLICIES (2010), available at http://www.euro.who.int/ data/assets/pdf file/0011/120143/E94241.pdf; Priya Sharma \& Adrian Towse, New Drugs to Tackle Antimicrobial Resistance: Analysis of EU Policy Options, UNITED KINGDOM OFFICE OF HEALTH ECONOMICS (2011), available at http://ohe.org/publications/article/new-drugs-to-tackle-antimicrobial-resistance$\frac{5 . \mathrm{cfm}}{17}$.

${ }^{\frac{5 . c f}{17} \text { Outterson, supra note } 15 \text {, at } 633 .}$

${ }^{18}$ Kesselheim \& Outterson, supra note 4, at 107.

${ }^{19} \mathrm{Id}$.

${ }^{20}$ See Mossialos et al., supra note 17; Sharma \& Towse, supra note 17.

${ }^{21}$ Sharma \& Towse, supra note 17 , at 30 .

${ }^{22}$ None of the proposals discussed in this note rely on tort-based mechanisms. For a discussion of tort-based models to combat antibiotic resistance, see Kesselheim \& Outterson, supra note 4.

${ }^{23}$ See, e.g., Eric Kades, Preserving a Precious Resource: Rationalizing the Use of Antibiotics, 99 Nw. U. L. REV. 611 (2005).
} 
market exclusivity. ${ }^{24}$ Commentators typically view PTEs as pull incentives because PTEs increase the size of the reward for development of a new antibiotic. Because antibiotic markets are not lucrative, however, the marginal increase in value of an extended antibiotic patent term is unlikely to attract drug companies' interest. ${ }^{25}$ Consequently, many commentators have proposed a variation of the PTE in which the extended rights are transferable to any patented drug and exchangeable between parties. ${ }^{26}$ A so-called "wildcard" PTE has the potential for high profitability and may therefore have a shorter duration than a PTE linked to sales of the new antibiotic. ${ }^{27}$ Some commentators believe that extensions of six months to two years are appropriate. $^{28}$ The financial appeal of a wildcard PTE is significant: a six-month PTE on Lipitor, the top-earning drug in the United States, was recently estimated to be worth over $\$ 3$ billion. $^{29}$

Critics believe that PTEs are not the right solution to a potential antibiotic shortage for a variety of reasons. One criticism centers on the public cost that PTEs impose by extending patent monopolies and delaying entry of generic drugs into the largest markets. ${ }^{30}$ By one estimate, the cost to the public of a two-year wildcard PTE is approximately $\$ 10$ billion, whereas the pharmaceutical industry estimates that the private cost of developing a new antibiotic is approximately $\$ 800$ million. ${ }^{31}$ PTE advocates argue, however, that shortening the extension to six months would decrease the public cost by $75 \%$ to $\$ 2.5$ billion. ${ }^{32}$ Moreover, a critic of PTEs

\footnotetext{
${ }^{24}$ See Infectious Diseases Society of America, Bad Bugs, No Drugs: As Antibiotic Discovery Stagnates . . A Public Health Crisis Brews, INFECTIOUS DISEASES SOCIETY OF AMERICA 26 (July 2004), available at http://www.fda.gov/ohrms/dockets/dockets/04s0233/04s-0233-c000005-03-IDSA-vol1.pdf.

${ }^{25}$ Sharma \& Towse, supra note 17 , at 35-36.

${ }^{26}$ See, e.g., Jorn Sonderholm, Wild-Card Patent Extensions as a Means to Incentivize Research and Development of Antibiotics, 37 J.L. MED. \& ETHICs 240 (2009); Spellberg, supra note 8, at 161.

${ }^{27}$ Sharma \& Towse, supra note 17 , at 40-42.

${ }^{28}$ Id. at 38 .

${ }^{29}$ Sonderholm, supra note 27 , at 241.

${ }^{30}$ See id.

${ }^{31}$ Id.; Joseph A. DiMasi et al., The Price of Innovation: New Estimates of Drug Development Costs, 22 J. HEALTH ECON., 151, 166 (2003).

${ }^{32}$ Kevin Outterson et al., Will Longer Antimicrobial Patents Improve General Global Public Health?, 7 LANCET INFECTIOUS DISEASES 559, 561 (2007); Sonderholm, supra note 27, at 242.
} 
concedes that "the market undervalues antibiotics" 33 and has proposed, as part of an alternative model to promote antibiotic effectiveness, "a very substantial increase in payments for antibiotics." 34 Thus, without a realistic estimate of the value of a new antibiotic, it is uncertain whether PTEs for new antibiotics impose an unduly high public cost.

A related criticism of wildcard PTEs is that they unfairly transfer the cost of developing a new antibiotic onto another group of patients with an unrelated ailment. ${ }^{35}$ According to this critique, the small segment of the population that must continue to pay monopoly drug prices due to the transferred extension bears the cost of providing a new antibiotic for everyone. ${ }^{36}$ Advocates counter that patients who need the drug to which the wildcard PTE is transferred will not disproportionately bear the cost of antibiotic development for two reasons: most patients have health insurance, and those who do not are still able to receive public health care. ${ }^{37}$ Consequently, the general public will ultimately pay for the antibiotic via health insurance rates and taxes. $^{38}$

Other criticisms of PTEs are more difficult to rebut. One is that the reward conferred by wildcard PTEs for the discovery of a new antibiotic is essentially arbitrary. ${ }^{39}$ With wildcard PTEs, the reward for a new antibiotic depends largely on factors such as timing that have no relation to the value of the antibiotic. For example, an early developer of a relatively modest antibiotic may receive a huge reward by selling its PTE to the owner of a blockbuster that is about to lose patent protection. A later developer of a truly innovative antibiotic may receive a much smaller reward because no blockbusters with expiring patents are available at that time. ${ }^{40}$

\footnotetext{
${ }^{33}$ Kesselheim \& Outterson, supra note 4, at 150.

${ }^{34} \mathrm{Id}$. at 152 .

${ }^{35}$ Outterson et al., supra note 33, at 562.

${ }^{36} \mathrm{Id}$. The authors posit that a PTE for a new antibiotic would likely be transferred to the cholesterol-lowering drug Lipitor and therefore call wildcard PTEs "a hidden tax on heart disease."

37 Sonderholm, supra note 27 , at 243.

${ }^{38} \mathrm{Id}$. This argument has become more compelling since the passage of the Patient Protection and Affordable Care Act of 2009, which requires all individuals to have health insurance.

${ }^{39}$ Id.

${ }^{40}$ Outterson et al., supra note 33, at 562.
} 
A related concern is that wildcard PTEs may trigger patent races in which developers invest large sums to be the first to deliver a new antibiotic. ${ }^{41}$ The costs of research and development in such races "overwhelm the social value of obtaining the [new antibiotic] a day or a month sooner." 42

\section{Government-based antibiotic development.}

Another property-based model to promote antibiotic development and conservation is to charge the government with these duties. ${ }^{43}$ According to this proposal, the government not only funds early-stage antibiotic discovery but "also perform[s] later-stage development and clinical testing, so that it can develop antibiotics itself." ${ }^{44}$ Whereas PTEs create stronger property rights for antibiotics, this model eliminates antibiotic property rights entirely. This model also entails a role for the government in antibiotic conservation via regulation. ${ }^{45}$ The primary criticism of this model is that the government lacks the expertise and experience to develop new antibiotics. ${ }^{46}$ As one analyst points out, "No government has successfully discovered and developed an antibiotic, and it is unlikely that any public body would have the resources or technical ability to do this." 47

\section{B. REgulation-BASED MODELS}

\section{Tax credits.}

Regulation-based models for antibiotic development and conservation, compared to the government-only approach described supra Part IIA, envision a more modest, but still expanded, role for the government. One such model is to award tax credits to companies that invest in

\footnotetext{
${ }^{41}$ Amy Kapczynski, Innovation Policy for a New Era, 37 J.L. MED. \& ETHICs 264, 266 (2009).

${ }^{42} I d$.

${ }^{43}$ Jessica P. Schulman, Patents and Public Health: The Problems with Using Patent Law Proposals to Combat Antibiotic Resistance, 59 DEPAUL L. REV. 221, 254 (2009).

${ }^{44}$ Id.

${ }^{45}$ See id. at 252 (stating that "[ $\left.\mathrm{t}\right]$ he best way to both slow the spread of antibiotic resistance and effectively use existing antibiotics involves closely regulating antibiotic use ....").

${ }^{46}$ E. Power, Impact of Antibiotic Restrictions: The Pharmaceutical Perspective, 12 CLINICAL MICROBIOLOGY AND INFECTION (Supp. 5) 25, 30 (2006), available at http://onlinelibrary.wiley.com/doi/10.1111/j.14690691.2006.01528.x/abstract.

${ }^{47} \mathrm{Id}$.
} 
antibiotic research and development. ${ }^{48}$ Tax credits operate as push incentives by reducing the barrier to entry into antibiotic markets. Tax credits relieve a company of some percentage of the tax burden on its revenues and are therefore attractive to large firms that already have products on the market. ${ }^{49}$ However, mechanisms exist to make tax credits more attractive to smaller companies. For example, the tax credit can be transferable or even redeemable as a cash refund for a company with low tax bills. ${ }^{50}$ Advocates contend that tax credits introduce fewer market distortions than other mechanisms that require direct government intervention and therefore result in lower transactional costs. ${ }^{51}$ The Orphan Drug Act (ODA), which sought to incentivize drug companies to develop drugs with weak market appeal, includes a tax credit, among other incentives. $^{52}$ Analysts believe that the tax credit has contributed to the ODA's success at spurring drug companies, including smaller ones, to develop new drugs for unmet medical needs. ${ }^{53}$ The Infectious Diseases Society of America (IDSA) also publicly endorsed tax credits for antibiotic research and development. ${ }^{54}$

Analysts have raised several criticisms of tax credits. First, as with any push incentive, a tax credit does not guarantee the delivery of a new product. ${ }^{55}$ Second, some commentators consider tax credits to be expensive gifts to developers because the public already pays for innovation through patent-protected monopolies. ${ }^{56}$ Third, companies seeking tax credits may "employ[] creative accounting" in reporting their investments. ${ }^{57}$ Thus, tax credits require the government to monitor companies closely, and the increased administrative costs may offset the

\footnotetext{
${ }^{48}$ Carl Nathan \& Frederick M. Goldberg, The Profit Problem in Antibiotic $R \&$ \& 4 NATURE R. DRUG DISCOVERY 887,890 (2005).

${ }^{49}$ Sharma \& Towse, supra note 17 , at 40.

${ }^{50}$ Mossialos et al., supra note 17 , at 79.

${ }^{51}$ Id. at 81 .

5226 U.S.C. § 45C (2006).

${ }^{53}$ Sharma \& Towse, supra note 17 , at 41.

${ }^{54}$ Spellberg, supra note 8, at 160.

${ }^{55}$ Mossialos et al., supra note 17, at 81.

${ }^{56}$ See id. (stating that "governments pay twice for elements of innovation.").

${ }^{57}$ Id.
} 
savings in transactional costs. ${ }^{58}$

\section{Expedited regulatory review.}

Another regulatory mechanism that could promote antibiotic development is expedited regulatory review. The fast-track option (FTO) is the mechanism of expedited regulatory review that has the greatest potential for impact on antibiotic development. The FTO mechanism entails consultation between the FDA and drug sponsor to make both the clinical and regulatory approval phases of development more efficient. ${ }^{59}$ The FTO process could shorten the time required to get a drug approved by as much as three years. ${ }^{60}$ Although an FTO could be applied directly to development of a new antibiotic, the FDA can best capture its value by selling the FTO to a company that applies the FTO to the drug of its choice. For example, a recent study modeled the hypothetical value of purchasing an FTO for Prozac that would have expedited the approval process by two years and found that it would have been worth between $\$ 500-750$ million. ${ }^{61}$

The FTO can operate as either a push or pull incentive. ${ }^{62}$ One commentator has proposed the use of FTOs by the European Medicines Agency (EMA), the counterpart to the FDA, as a push mechanism to raise money for research on neglected diseases. ${ }^{63}$ According to this model, the EMA auctions an FTO to the highest bidder and uses the resulting funds to support research and development on neglected diseases. ${ }^{64}$ Alternatively, others have suggested the use of FTOs as a pull incentive by awarding an FTO to a company that brings a new antibiotic to market. ${ }^{65} \mathrm{~A}$

\footnotetext{
${ }^{58} \mathrm{Id}$.

${ }^{59}$ Mary Moran, Fast Track Options as a Fundraising Mechanism to Support $R$ \& D into Neglected Diseases, PhARM. R\&D POL'y PROJECT LONDON SCHOOL OF ECON. 2-3 (2005), available at http://www.who.int/intellectualproperty/submissions/Mary.Moran2.pdf.

${ }^{60} \mathrm{Id}$. at 4.

${ }^{61}$ Id . at 12. Modeling assumed that FTO was purchased five years prior to approval. Applying FTO to new drug candidate carries the risk that candidate will not get approval, so the modeling included alternative calculations based on assumptions that either Prozac was certain to get approved (no risk) or that risk could be estimated. Assumption of no risk produced value of \$761 million, and estimation of risk produced value of \$521 million.

${ }^{62}$ Sharma \& Towse, supra note 17 , at 31.

${ }^{63}$ See Moran, supra note 60, at 2-6.

${ }^{64} I d$. at 4-6.

${ }^{65}$ Sharma \& Towse, supra note 17 , at 31.
} 
premise of this model is that the FTO is transferable so that any company can realize the value of the FTO, regardless of whether the company has its own blockbuster. ${ }^{66}$

The potential sale of fast-track review by the FDA to raise money for antibiotic development triggers three concerns. Foremost is whether the expedited clinical and regulatory review would result in bringing unsafe drugs to market. ${ }^{67}$ Defenders argue that even if expedited review creates increased risk, FTOs would produce a net health gain: the benefit of having a new antibiotic would more than offset the safety costs of bringing a second drug to market via expedited review. ${ }^{68}$ A second concern is the societal cost of effectively extending monopoly pricing of the drug to which the FTO transferred. ${ }^{69}$ Like a wildcard PTE, the transferable FTO could be viewed as a tax on patients suffering from a specific disease (treated by the fast-tracked drug) to pay for antibiotics for everyone. ${ }^{70}$ However, the same counterargument for PTEs applies to FTOs: the increased costs of the blockbuster are ultimately distributed to the public through health insurance rates and taxes. ${ }^{71}$

\section{Changes in FDA approval guidelines.}

Another proposed regulatory mechanism to facilitate delivery of new antibiotics is to simplify the regulatory review process to obtain FDA approval of antibiotics. ${ }^{72}$ One recommendation is to increase FDA guidance to drug developers about the types of clinical studies and evidence required to prove safety and efficacy of a new antibiotic. ${ }^{73}$ For example, the FDA has made several changes to the standard of non-inferiority, including both relaxation and clarification, over the last twenty years. ${ }^{74}$ The lack of certainty in the standard for approval

\footnotetext{
${ }^{66} \mathrm{Id}$.

${ }^{67}$ Id. at 33 .

${ }^{68}$ Tomas J. Philipson et al., Assessing the Safety and Efficacy of the FDA: The Case of the Prescription Drug User Fee Acts, NAT'L BUREAU OF ECON. RESEARCH 8-16 (2005), available at http://www.nber.org/papers/w11724.pdf?new_window=1.

${ }^{69}$ Sharma \& Towse, supra note 17 , at 33.

${ }^{70}$ See Outterson et al., supra note 33, at 562.

${ }^{71}$ See Sonderholm, supra note 27, at 243.

${ }^{72}$ Mossialos et al., supra note 17, at 152; Power, supra note 47, at 28-29.

${ }^{73}$ Spellberg, supra note 8 , at 158 .

${ }^{74}$ For a description of changes in the FDA's standard of non-inferiority, see Power supra note 47, at 28-29.
} 
may dissuade potential antibiotic developers, who could face large unanticipated increases in costs after they are far along in the development process. ${ }^{75}$ Consequently, some commentators "strongly recommen[d] that further progress be made towards providing developers with clear and consistent guidance for trials for relevant indications." ${ }^{, 76}$

Critics fear that relaxing or simplifying FDA guidelines for antibiotic approval could have a net negative effect on public health. Loosening the regulatory requirements for new antibiotics could assist the fight against infectious diseases, but would likely result in an increase in adverse side effects that may outweigh the benefits. ${ }^{77}$ Significantly, more than half of the antibiotics approved by the FDA from 1980-2000 were subsequently removed from the market, many of them due to safety concerns; relaxation of standards for approval would likely exacerbate this problem. $^{78}$ Clarification of FDA standards for antibiotic approval also carries risk. Firm, clear guidelines intended to facilitate approval of antibiotics may have the opposite effect. For example, when an indication for an antibiotic is defined narrowly, the developer may have difficulty obtaining a sufficient number of patients for a clinical study, resulting in delayed approval of a much-needed antibiotic. The market introduction of daptomycin illustrates this point. ${ }^{79}$ Thus, bright-line rules for antibiotic approval may deprive the agency of the discretion it needs to approve important new antibiotics like daptomycin.

\section{Waiver of antitrust laws.}

Another regulatory mechanism to secure the antibiotic supply is to grant a limited waiver of antitrust laws to allow companies to coordinate sales of antibiotics. ${ }^{80}$ Whereas most of the models discussed here incentivize antibiotic development, this proposal focuses primarily on

\footnotetext{
${ }^{75} \mathrm{Id}$. at 29.

${ }^{76}$ Mossialos et al., supra note 17 , at 152.

${ }^{77}$ See Kesselheim \& Outterson, supra note 4, at 145-46.

${ }^{78} I d$. at 146.

${ }^{79}$ For a description of daptomycin's path to approval, see Helen W. Boucher, Challenges in Anti-Infective Development in the Era of Bad Bugs, No Drugs: A Regulatory Perspective Using the Example of Bloodstream Infection as an Indication, 50 CLINICAL INFECTIOUS DISEASES (Supp. 1) S4, S5-S8 (2010).

${ }^{80}$ Kesselheim \& Outterson, supra note 4, at 157.
} 
antibiotic conservation. The basis for this proposal is that the biological mechanisms of antibiotic resistance often confer broad resistance to an entire class of antibiotics, so producers of different antibiotics within a given class may need to act collectively to stave off resistance. ${ }^{81}$ According to this proposal, the FDA identifies combinations of antibiotics and infectious bacteria for which cross-resistance is a problem. ${ }^{82}$ The FDA then issues certificates to the patent holders of the antibiotics in a given class that immunize these companies from antitrust prosecution as long as they meet specified conservation goals. ${ }^{83}$ The proposal also contemplates PTEs as potentially necessary to prevent generic producers from entering the market and interfering with conservation efforts. ${ }^{84}$

Implementation of antitrust waivers for antibiotic classes to promote antibiotic conservation poses two challenges. First, coordinated sales between drug companies can only preserve antibiotic effectiveness if other stakeholders commit to the effort as well. ${ }^{85}$ Hospitals, physicians, and other health care providers must be willing to change their practices in using antibiotics. ${ }^{86}$ Thus, promoting antibiotic conservation would require not only horizontal coordination among competing suppliers but also vertical coordination among actors at different levels in the supply chain. ${ }^{87}$ Advocates of antitrust waivers point out that both types of transactions may need protection from antitrust laws. ${ }^{88}$ Second, the success of antibiotic conservation through coordinated sales within antibiotic classes depends on the strength of the science upon which the classification relies. Mechanisms of resistance to a new antibiotic may be unknown; consequently, an antibiotic initially believed to be an orphan may later be identified as a member of a pre-existing class. Unchecked marketing of a single antibiotic from a

\footnotetext{
${ }^{81}$ Id. at $157-58$.

${ }^{82} \mathrm{Id}$. at 158 .

${ }^{83} \mathrm{Id}$.

${ }^{84} \mathrm{Id}$.

${ }^{85}$ Id. at 159.

${ }^{86}$ Kesselheim \& Outterson, supra note 4, at 159.

${ }^{87}$ Id.

${ }^{88}$ Id. at $157-59$.
} 
resistance class could undermine the conservation efforts of a host of other companies and curtail their financial rewards.

\section{Contract-BASEd Models}

\section{Direct funding of research.}

The largest category of proposals to combat an antibiotic shortage comprises models that rely on contractual arrangements with the government. One contract-based push incentive that has long been used to stimulate antibiotic research and development is direct government funding of antibiotic-related research. The National Institute of Allergy and Infectious Diseases (NIAID) is the main body that funds research on infectious diseases in the United States. ${ }^{89}$ In 2007, the NIAID invested approximately $\$ 800$ million in antimicrobial research (including study of both bacterial and viral pathogens), about $\$ 200$ million of which was dedicated to the study of antimicrobial resistance. ${ }^{90}$ This funding primarily supports academic institutions and intramural programs, although private companies receive some of this money through product development partnerships (PDPs, see infra Part II.C.4). For example, Project Bioshield allocated \$5.6 billion over a ten-year period for research on antibiotics that could be used as defenses against acts of bioterrorism. $^{91}$ More recently, the IDSA recommended increased grant funding for antibiotic research generally to the House Committee on Energy and Commerce. ${ }^{92}$

Few proposals to solve the potential antibiotic shortage rely on direct research funding because it suffers from a variety of problems. One weakness is that the information asymmetry between the funding agency and researcher may cause the latter to exaggerate the promise of a

\footnotetext{
${ }^{89}$ Who We Are and What We Do, NATIONAL InSTITUTE FOR ALLERGY AND INFECTIOUS DiSEASES, http://www.niaid.nih.gov/about/Pages/default.aspx (last updated Feb. 29, 2012).

${ }^{90}$ N. Kent Peters et al., The Research Agenda of the National Institute of Allergy and Infectious Diseases for Antimicrobial Resistance, 197 J.INFECTIOUS DISEASES 1087, 1087-88 (2011).

${ }^{91}$ Project Bioshield Act of 2004, Pub. L. No. 108-276, 118 Stat. 835 (codified in 6 U.S.C. $\S 320$ and 42 U.S.C. $\S$ 247d-6); Office of the Assistant Sec'y for Preparedness and Response, Biomedical Advanced Research and Development Auth., U.S. Dep't. of Health and Human Serv., 110th Cong., Project BioShield: Annual Report to Congress Aug. 2006 - July 2007, 10 (2007).

${ }^{92}$ Antibiotic Hearing, supra note 2, at 13-14. 
drug candidate. ${ }^{93}$ Government bodies may not be qualified to assess the viability of grant applications and may therefore misallocate resources. ${ }^{94}$ Another potential problem is that direct government funding may lack the long-term stability needed to support ongoing antibiotic development due to political variables. ${ }^{95}$ As one group put it, "government funding is often set on an annual basis and is thus dependent on the individuals in power, the economic climate, and other perpetually changing factors." 96 The apprehension of funding instability may, however, be overwrought. For example, annual funding for antimicrobial research rose steadily over the tenyear period from 1998-2007..$^{97}$ A third concern, common to all push incentives, is the lack of incentive to deliver a final product. ${ }^{98}$ As one group of analysts points out, a developer who receives an upfront payment "may lack the motivation to continue development once [it has] reached the end of the push funding." 99

\section{Advance purchase commitments.}

Another contract-based mechanism to stimulate antibiotic development is the advanced purchase commitment (APC), which is also called the advanced market commitment. An APC is a promise by the government to purchase a fixed quantity of an antibiotic that meets certain specifications at a price attractive to drug developers. ${ }^{100}$ One predicate of success for an APC is the developer's agreement to continue to sell the antibiotic at a reasonable price once the APC has expired. ${ }^{101}$ The IDSA has advocated for APCs as one component of a multidimensional proposal to stimulate antibiotic development. ${ }^{102}$

APCs face several barriers to implementation. The first is the difficulty of determining

\footnotetext{
${ }^{93}$ Mossialos et al., supra note 17, at 77; Sharma \& Towse, supra note 17, at 23.

${ }^{94}$ Mossialos et al., supra note 17 , at 77.

${ }^{95} \mathrm{Id}$.

${ }^{96} \mathrm{Id}$.

${ }^{97}$ Peters et al., supra note 91, at 1088.

${ }^{98}$ Sharma \& Towse, supra note 17, at 23.

${ }^{99}$ Id.

${ }^{100}$ See Michael Kremer \& Rachel Glennerster, Strong Medicine: Creating Incentives for Pharmaceutical ReSEARCH ON Neglected DiSEASES 68-69 (Princeton Univ. Press 2004).

${ }^{101}$ Sharma \& Towse, supra note 17, at 27.

${ }^{102}$ Spellberg, supra note 8, at 160.
} 
the size and price of the APC: too small a purchase fails to provide adequate incentive for drug developers, whereas too large a purchase risks wasting government resources. ${ }^{103}$ A second problem is deciding whether the APC should be awarded only to the first developer of an antibiotic in a given class or be split among multiple companies that have developed antibiotics with similar characteristics at approximately the same time. ${ }^{104}$ The former approach would offer no reward for a later-developed antibiotic that might have advantageous properties compared to the pioneer of that class, a common scenario in antibiotic development. ${ }^{105}$ The latter strategy, however, could be difficult to administer and would make the incentive smaller and less certain. $^{106}$ Another problem, common to all pull incentives that rely on direct government payments, is the political hurdle of securing a firm commitment from the government to pay for a future product that may never be delivered. A recent estimate indicates that a commitment of \$2.3 billion would be required to provide adequate incentive for development of a new antibiotic. $^{107}$ Moreover, enacting legislation to allocate funds to buy as-yet undeveloped antibiotics may be the most difficult political step in implementing an APC, but it would not be the last. Due to the length of time required to develop a new drug, the credibility of an APC to prospective developers would depend on a stable, ongoing commitment from the government. ${ }^{108}$ "One could envision government budgetary pressures combined with the appearance of windfall profits . . . leading to a downward spiral in prices."109

\section{Prizes.}

A third contract-based model for stimulating antibiotic development is for the government to offer monetary prizes for new antibiotics. Prize systems for approved new antibiotics can take three forms. In the first form, the prize system replaces patent rights

\footnotetext{
${ }^{103}$ Sharma \& Towse, supra note 17 , at 28.

${ }^{104} \mathrm{Id}$ at 27.

${ }^{105} \mathrm{Id}$.

${ }^{106} I d$.

${ }^{107} I d$. at 29.

${ }^{108}$ See Henry Grabowski, Encouraging The Development Of New Vaccines, 24 HEALTH AfFAIRs 697, 698 (2005). ${ }^{109} I d$.
} 
altogether. ${ }^{110}$ Senator Bernie Sanders (I-Vt.) has proposed such a prize model for drugs to treat neglected disease in three Congressional bills: the Medical Prize Innovation Act of 2005, the Medical Prize Innovation Act of 2007, and the Medical Prize Fund Innovation Act of 2011. ${ }^{111}$ In this model, the developer of a new drug is entitled to a large cash reward but may not receive intellectual property protection for the pharmaceutical. ${ }^{112}$ The size of the award depends on several factors, such as the health impact of the drug, its incremental benefit over existing medicines, and whether development of the new drug is based on previous innovations. ${ }^{113}$ The second type of prize system offers a smaller reward for the first company to market a new antibiotic but allows the developer to retain patent rights. ${ }^{114}$ This option provides a strong incentive for developers to reach the market quickly and places a smaller financial burden on the government. $^{115}$ The third form is an optional prize system in which the developer can choose between receiving a reward and obtaining patent rights. ${ }^{116}$ The Health Impact Fund (HIF) is a proposal for an optional international prize fund for drugs to treat neglected diseases. ${ }^{117}$

Each type of prize system has its drawbacks. The major obstacle for a mandatory prize system, as evidenced by the fate of the Sanders' MIPFA bills, is the political unattractiveness of its high cost. The cost of the Medical Innovation Prize Fund Act (MIPFA), the 2011 Sanders' bill, was $\$ 80$ billion, $0.55 \%$ of the gross domestic product. ${ }^{118}$ Voters and legislators may be hesitant to earmark such large sums for future payouts, and pharmaceutical companies might balk at relinquishing their patent rights. Another potential problem of a mandatory prize system

\footnotetext{
${ }^{110}$ Mossialos et al., supra note 17 , at 91 .

${ }^{111}$ Medical Innovation Prize Act of 2005, H.R. 417, 109th Cong. (2005); Medical Innovation Prize Act of 2007 , S. 2210, 110th Cong. (2007); Medical Innovation Prize Fund Act, S. 1137, 112th Cong. (2011). Sanders was a member of the House of Representatives when he introduced the Medical Innovation Prize Act of 2005.

${ }_{112}$ Medical Innovation Prize Fund Act, S. 1137, 112th Cong. (2011).

${ }^{113}$ Id. $\S 9(\mathrm{c})$.

${ }^{114}$ Mossialos et al., supra note 17, at 93.

${ }^{115} \mathrm{Id}$.

${ }^{116}$ Id.; See also Steven Shavell \& Tanguy van Ypersele, Rewards Versus Intellectual Property Rights, 44 J.L. \& ECON. 525 (2001).

${ }^{117}$ Aidan Hollis \& Thomas Pogge, The Health Impact Fund: MaKing New Medicines ACCESSIBLE FOR All 13-24 (Incentives for Global Health 2008).

${ }^{118}$ Medical Innovation Prize Fund Act, S. 2210, 110th Cong. § 2(4) (2011).
} 
in which private companies forego patent rights is that the lack of monopoly control would lead to higher sales. An antibiotic priced at its marginal cost from the moment it hits the market would face a higher consumer demand, which would accelerate the development of resistance and shorten the effective lifespan of the antibiotic. ${ }^{119}$ In contrast, the primary criticism of a prize system in which private patent rights are retained is that the public has to pay for the new antibiotic twice: once through taxes for the prize, and a second time through the market for monopoly prices. ${ }^{120}$ Finally, the optional prize system has been attacked for its inefficiency in the context of drug development generally. ${ }^{121}$ According to one analyst, companies will only opt for the reward if they believe that the government is willing to pay more for a drug than it is worth, so the public will always end up overpaying. ${ }^{122}$ As discussed supra Part I, however, some commentators believe that the market undervalues antibiotics both for their primary patient benefits and for their positive secondary health effects. ${ }^{123}$ Consequently, this concern may not apply to antibiotics.

\section{Publicly-sponsored early-stage research collaborations.}

Another category of contractual models to promote antibiotic development comprises various research collaborations between public and private entities. The goal of such proposals is to better integrate different phases of antibiotic research that have traditionally occurred in separate spheres: fundamental scientific discoveries in academia, and development of drug candidates in biotechnology and pharmaceutical companies. ${ }^{124}$ Public-private partnerships (PPPs), also called product development partnerships (PDPs), have been a critical step in this direction. $^{125}$ PPPs are contractual research collaborations between publicly-funded research

\footnotetext{
${ }^{119}$ Kades, supra note 24, at 646-47.

${ }^{120}$ Mossialos et al., supra note 17 , at 93.

${ }^{121}$ See Michael Abramowicz, Perfecting Patent Prizes, 56 VAND. L. REV. 115, 123 (2003).

${ }^{122} \mathrm{Id}$.

${ }^{123}$ Outterson, supra note 15 , at 629.

${ }_{125}^{124}$ See Carl Nathan, Aligning Pharmaceutical Innovation with Medical Need, 13 NAT. MED. 304, 305 (2007). ${ }^{125} \mathrm{Id}$.
} 
organizations and private pharmaceutical companies. ${ }^{126}$ Although PPPs vary widely in form, they are typically formed when a public organization has identified a promising drug candidate in its discovery research and seeks a private partner to develop the compound. ${ }^{127}$ In the partnership, the public partner provides the funding, and the private partner contributes expertise in drug development. ${ }^{128}$

Another proposed collaborative model is the "open-access drug company."129 According to one commentator, optimal drug development requires ongoing interaction between scientists doing discovery-phase research and those involved in later stages of development; the exchange of information and resources between the two groups makes the entire process more efficient. ${ }^{130}$ PPPs, however, limit the interaction between the early-stage and late-stage scientists, resulting in an "unnecessarily small number of what are likely to be suboptimal lead compounds."131 An alternative is the open-access drug company, a more stable and integrated organization that allows free interaction among all interested parties from the outset. ${ }^{132}$ In such an arrangement, private drug companies provide information, certain proprietary materials (e.g., chemical libraries), and research space to government-funded academic scientists for a fee. ${ }^{133}$ The private partner in the open access company benefits from the results of custom-tailored drug discovery research but foregoes patent rights. ${ }^{134}$ The government or other public funding agency retains a limited set of rights to any newly-discovered compounds through a "track II" patent, another novel feature of this model. ${ }^{135}$ In contrast to a traditional patent ("track I" under this model), a track II patent would not confer the right to exclude others from selling the drug; instead, a track

\footnotetext{
${ }^{126}$ Mossialos et al., supra note 17 , at $82-83$.

${ }^{127}$ See, e.g., id. at 83-84.

${ }^{128}$ Id. at 83 .

${ }^{129}$ Nathan, supra note 125 , at 305.

${ }^{130} \mathrm{Id}$.

${ }^{131} \mathrm{Id}$.

${ }^{132} \mathrm{Id}$.

${ }^{133} \mathrm{Id}$.

${ }^{134} I d$. at 307.

${ }^{135} \mathrm{Id}$. at $305-07$.
} 
II patent would entitle its owner to receive periodic payments based on the health impact of the drug. ${ }^{136}$

The main concerns regarding early-stage research collaborations derive from the potential for misalignment of incentives of the different parties. First, PPPs create unique governance problems that result from goals of the constituent organizations that are not always shared. ${ }^{137}$ Analysts have identified a number of issues that contribute to poor governance of PPPs: failure to specify partners' roles and responsibilities, inadequate monitoring of performance, insufficient oversight in partner selection and management of conflicts of interest, and lack of transparency in decision-making. ${ }^{138}$ A second problem is the information asymmetry at the time of PPP formation. $^{139}$ According to some commentators, a scientist with a drug candidate looking to form a PPP "knows far more about the product's likelihood of success [than do the industrial scientists with whom he would like to collaborate] and may be prone to over-emphasize its potential."140 For open-access drug companies, a potential conflict exists between the scientists who develop the patented drugs and the funders to whom the inventors obligatorily contract their patent rights. ${ }^{141}$ Because the interests of various stakeholders may be incompatible, some analysts believe it is unclear "[a]t what stage they will compete and at what stage they will collaborate." 142

\section{Reimbursement.}

Another contract-based model to promote antibiotic development and conservation is for government agencies to increase insurance reimbursement for antibiotics. Again, as discussed supra Part I, some commentators believe that the market undervalues antibiotics compared to

\footnotetext{
${ }^{136} I d$. at 307 .

${ }^{137}$ Kent Buse \& Andrew M. Harmer, Seven Habits of Highly Effective Global Public-Private Health Partnerships: Practice and Potential, 64 SOCIAL SCIENCE \& MEDICINE 259, 264 (2007).

${ }^{138} I d$.

${ }^{139}$ Mossialos et al., supra note 17 , at 87.

${ }^{140} \mathrm{Id}$.

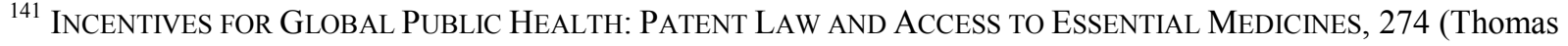
Pogge, Matthew Rimmer, \& Kim Rubenstein, eds., Cambridge University Press 2010). 
their social value. ${ }^{143}$ To correct this market flaw, they propose that a government agency aided by experts from Medicare choose an appropriate system for calculating the social value of antibiotics and adjust insurance reimbursement rates accordingly. ${ }^{144}$ So-called "value-based reimbursement" would cause antibiotic prices to rise substantially, likely resulting in a simultaneous increase in sales revenue and decrease in sales volume. ${ }^{145}$ Thus, value-based reimbursement could incentivize both development of new antibiotics and conservation of existing ones. $^{146}$

The primary concern with value-based reimbursement is the choice of metric for calculating the appropriate price for antibiotics. ${ }^{147}$ Advocates of value-based reimbursement recommend using disability-adjusted life years (DALYs) as a measure for social value, although quality-adjusted life years (QALYs) and other potential metrics exist. ${ }^{148}$ Others believe that development of an entirely new, "more holistic" system may be necessary. ${ }^{149}$ Even skeptics concede, however, that adoption of an imperfect metric until a better system is devised would help in the short term to lure developers into the antibiotic field. ${ }^{150}$

\section{A New Model for Uncoupling Antibiotic Development from Sales (UADS)}

\section{A. OVERVIEW OF UADS MODEL}

In light of the strengths and weaknesses of these models to secure the future antibiotic supply, this article describes a system for uncoupling antibiotic development and sales (UADS). The UADS model incorporates ideas from several previous proposals into a system designed to

\footnotetext{
${ }^{143}$ Kesselheim \& Outterson, supra note 4, at 150.

${ }^{144} \mathrm{Id}$. at $152-53$.

145 Id. at 152 .

${ }^{146}$ For a fuller description of how higher reimbursement for antibiotics would affect the behavior of drug companies, physicians, and patients see Outterson, supra note 14, at 646-55.

${ }_{147}$ See Mossialos et al., supra note 17, at 121-25.

${ }^{148}$ See Kesselheim \& Outterson, supra note 3, at 150-53. For a detailed discussion of quantification of qualityadjusted life years, see HoLLIS \& POGGE, supra note 117, at 27-35.

${ }_{149}$ Mossialos et al., supra note 17 , at 123 .

${ }^{150} I d$. at 123 .
} 
address the unique combination of problems that confront developers of antibiotics. As the name suggests, the essential feature of this model is the uncoupling of antibiotic development from production and sales so that the incentives for antibiotic innovation and conservation are no longer misaligned. Instead, development and sales occur in two separate phases by two different sets of actors.

The motivating force in the development phase (phase one) of the UADS model is a patent buyout. ${ }^{151}$ In phase one, pharmaceutical and biotechnology companies and PPPs develop new antibiotics and seek patent protection for the new compounds, formulations, or methods of use. To receive FDA approval for new antibiotics, developers must transfer their patent rights to the government in exchange for a substantial prize. Because FDA approval is conditioned upon relinquishing patent rights, participation in the prize system is, for practical purposes, mandatory. In the patent buyout in phase one, new antibiotics are not released into the public domain by eliminating patent rights altogether; rather, the government retains the rights for use during the sales phase.

The crux of the sales phase (phase two) is that the government licenses the patent rights to drug manufacturers to make and sell the antibiotics. Although the same company could develop and produce a given drug, these two functions may also be performed by separate entities. For example, innovative biotechnology companies and pharmaceutical firms with experience in clinical development may be the strongest competitors in the development phase. In the sales phase, however, companies that specialize in manufacturing generic drugs may excel due to their experience at adapting rapidly to production of new compounds. The government also plays a critical role during the sales phase. By retaining rights in all new antibiotics through mandatory participation of developers, the government is well-positioned to promote antibiotic

\footnotetext{
${ }^{151}$ For descriptions of patent buyout systems, see Abramowicz, supra note 117; Shavell \& van Ypersele, supra note 166; Hollis \& PogGe, supra note 41; Michael Kremer, Patent Buyouts: A Mechanism for Encouraging Innovation, 113 Q.J. ECON. 1137 (1998).
} 
conservation. An administrative body such as the FDA would be able to decide such issues as priority of antibiotic use and appropriateness of indications unencumbered by conflicting private interests.

The UADS model is based on the prize system embodied in the MIPFA. ${ }^{152}$ As acknowledged in an earlier version of the bill, “[a]wards to companies . . . that reward successful product research can de-couple the reward for product research development from the price of the product." ${ }^{\prime 153}$ However, some objectives of the UADS model differ from those of the MIPFA as a result of the differences in scope of the two proposals. The MIPFA targets neglected diseases, whereas the UADS model focuses on bacterial infections. As discussed supra Part I, combating bacterial infections with antibiotics poses a special set of challenges. ${ }^{154}$ The declared purpose of the MIPFA is to enhance access to drugs by providing them to consumers at lower prices, but for antibiotics, both higher prices and decreased consumer access serve the public interest. ${ }^{155}$ The MIPFA recognized the unique dilemma that antibiotics pose, but the breadth of the bill precluded a detailed description of how to promote antibiotic conservation. ${ }^{156}$ Thus, phase two of the UADS model diverges from the vision of the MIPFA: the MIPFA is designed to increase distribution of new drugs generally, including antibiotics, whereas phase two of the UADS seeks to limit and regulate distribution of new antibiotics specifically. ${ }^{157}$

\section{B. Features of Phase ONE}

\section{Mandatory participation.}

One element of the UADS model is that participation is mandatory for all developers of antibiotics. As discussed supra Part II.C.3, others have proposed patent prize systems in which

\footnotetext{
${ }^{152}$ Medical Innovation Prize Fund Act, S. 1137, 112th Cong. (2011). For a detailed description of the prize system that gave rise to Medical Prize Innovation Act, see James Love \& Tim Hubbard, The Big Idea: Prizes to Stimulate R \& D for New Medicines, 82 CHI.-KENT L. REV. 1519 (2007).

${ }^{153}$ Medical Innovation Prize Act of 2007, S. 2210, 110th Cong. § 2(9) (2007).

154 Medical Innovation Prize Fund Act, S. 1137, 112th Cong. $\S \S(9)(c)(3)(C), 15(a)(2)(2011)$.

${ }^{155}$ Medical Innovation Prize Fund Act, S. 1137, 112 th Cong, $§ 3$ (2011). See Kesselheim \& Outterson, supra note 3 , at $150-53$.

${ }_{156}^{15}$ Medical Innovation Prize Fund Act, S. 1137, 112th Cong. § 9(c)(6) (2011).

157 Medical Innovation Prize Fund Act, S. 1137, 112th Cong. $§ 3$ (2011).
} 
participation is optional for producers of drugs for neglected diseases. ${ }^{158}$ However, a system that makes participation mandatory has several advantages in the context of antibiotic development. First, the problem of cross-resistance to different antibiotics within a class makes it necessary for coordinated regulation of all antibiotics by a central administrative body. ${ }^{159}$ As discussed infra Part III.C.3, the actions of a single antibiotic producer that chooses not to participate in the conservation effort but instead, aggressively markets its drug could create elevated resistance to an entire antibiotic class. Mandatory participation removes the possibility of misaligned incentives that create this negative externality. Second, "[v]oluntary prize mechanisms would also be [more] expensive, since companies could opt for the larger sum between monopoly profits or the prizes." ${ }^{\prime 60}$ In an optional system, a developer that knows it can receive a predictable return by registering for the prize can use that information to leverage a higher profitability from monopoly sales. In effect, the developer could use the prize to bargain with the public, which would pay either directly for the prize or indirectly via insurance rates and reimbursement. Making participation mandatory precludes developers from gaming the system in this way.

Implementation of a mandatory participation program requires a plan for the transition from the current system of private rights. The UADS model could adopt a transition plan similar in design to the one contained in the MIPFA. ${ }^{161}$ The MIPFA recommended distributing $90 \%$ of the prize fund to private patent holders during the first year and decreasing the allocation by $9 \%$ per year over a ten-year period. ${ }^{162}$ The balance of the fund that is not reserved for pre-existing private patent holders would be available for distribution to registrants of new drugs. The MIPFA also placed a ceiling of 5\% of the total annual fund value for any one drug registered

\footnotetext{
${ }^{158}$ See Abramowicz, supra note 117; Kremer, supra note 101; Shavell \& van Ypersele, supra note 117; HoLLIS \& PoGGE, supra note 41.

${ }^{159}$ See RAmANAN LAXMINARAyAn \& ANUP MALANI, EXTENDING THE CURE: PoliCy RESPONSES TO THE GROWING THREAT OF ANTIBIOTIC RESISTANCE 40-41 (2007).

${ }^{160}$ Love \& Hubbard, supra note 153, at 1535.

${ }_{161}$ Medical Innovation Prize Fund Act, S. 1137, 112th Cong. $§ 13$ (2011).

${ }^{162}$ Medical Innovation Prize Fund Act, S. 1137, 112th Cong. $§ 13$ (c) (2011).
} 
under the program. ${ }^{163}$ Thus, the MIPFA could award the maximum payment for up to two new drugs during the first transitional year, and this number would increase to twenty by the end of the ten-year transition period. Optimizing the transition for the UADS model may require some adjustment of the transitional parameters. For example, extending the transition period to fifteen or twenty years would mitigate the harm to current holders of antibiotic patents without adversely affecting the incentive for present and future developers. Additionally, raising the maximum percentage of the fund allocated for a single new compound may be necessary. The UADS model is narrower in scope than the MIPFA and would likely include a smaller number of drugs than the MIPFA anticipated. Therefore, the possibility of having twenty or more antibiotics simultaneously registered under the UADS model seems remote, particularly during the transition period. ${ }^{164}$ In addition, the budget for the UADS model would be smaller than for the MIPFA. Thus, raising the maximum award for an individual antibiotic above $5 \%$ of the total fund value might be appropriate for the UADS model.

\section{Prize options.}

Both the political viability and economic success of the UADS model depend on the size of the prize and how it is funded. The prize must be large enough to attract potential developers to invest in development of a product for which the private market has been inadequate. At the same time, the size of the outlay must not be politically unpalatable to voting constituencies who may already be skeptical of an unproven system. ${ }^{165}$ The mechanisms suggested here for funding and awarding prizes under the UADS proposal are taken directly from previous patent prize models for neglected diseases. ${ }^{166}$ The antibiotics market may provide an opportunity to test and perfect these ideas in a limited scope; a method that proves successful in the antibiotics arena

\footnotetext{
${ }^{163}$ Medical Innovation Prize Fund Act, S. 1137, 112th Cong. § 9(d)(4) (2011).

${ }^{164}$ Another factor that casts doubt on the likelihood of having twenty or more antibiotics simultaneously registered during the UADS transition period is the pharmaceutical industry's dearth of antibiotic development activity over the last three decades.

${ }^{165}$ Abramowicz, supra note 122, at 123.

${ }^{166}$ See Love \& Hubbard, supra note 153; Medical Innovation Prize Fund Act, S. 1137, 112th Cong. (2011); HoLLIS \& POGGE, supra note 118.
} 
may convince skeptics of the method's viability for a more expensive and expansive plan to cover neglected diseases generally.

Funding the prizes.

Funding for the UADS proposal would come from the federal budget. Due to the length of time required for development of new drugs, the UADS model requires a funding commitment for an extended period. ${ }^{167}$ The international HIF, focusing on the contribution of payers, recommends that participating countries commit to funding for a period of twelve years. ${ }^{168}$ Viewed from the perspective of prize recipients, the MIPFA envisioned that a prize winner would be eligible for annual payments for a maximum of ten years. ${ }^{169}$ Based on these models, a funding period of 10-15 years would be appropriate for the UADS model. Another question for the UADS model is whether the obligation of the payer (i.e., the federal government) or the expected payment to the prize recipient should be fixed. Developers of the MIPFA advocate the latter system because it facilitates budget planning by the government. ${ }^{170}$ Determination of the appropriate level of funding for the UADS program would be based on current national expenditures to treat bacterial diseases and foreseeable costs that would result from future antibiotic shortages. ${ }^{171}$

Distributing the prizes.

Several factors merit consideration in determining how to distribute UADS prizes. The most critical concern is how to determine the size of the prize for an individual developer. The HIF has a distribution model in which payment correlates directly to health impact (measured in

\footnotetext{
${ }^{167}$ See Steven M. Paul et al., How to Improve R\&D Productivity: The Pharmaceutical Industry's Grand Challenge, 9 NATURE REVIEWS DRUG Discovery 203, 205 (2010) (discovery and development of a new drug takes an average of 13.5 years).

${ }^{168}$ HoLLIS \& POGGE, supra note 118 , at 10.

${ }^{169}$ Medical Innovation Prize Fund Act, S. 1137, 112th Cong. § 9(d)(3) (2011).

${ }^{170}$ Love \& Hubbard, supra note 153, at 1536.

${ }^{171}$ An accurate estimate of these values would require calculations beyond the scope of this article, but it is worth noting that the level of funding required for the UADS model would be lower than the amount needed for either the HIF or MIPFA because the UADS model is narrower in scope: the UADS model covers only antibiotics, whereas the HIF and MIPFA cover drugs for all neglected diseases. Proposed funding levels for the HIF and MIPFA are $0.03 \%$ of gross national income and $0.55 \%$ of gross domestic product, respectively. HoLLIS \& POGGE, supra note 118, at 9; Medical Innovation Prize Fund Act, S. 1137, 112th Cong. § 17(a)(2) (2011).
} 
QALYs) of the new drug. ${ }^{172}$ Under UADS, however, the health impact of a new antibiotic may be impossible to measure accurately because the antibiotic may be held in reserve. For example, an antibiotic may be "stockpiled" as a defensive measure to a potential bio-terrorism attack or saved as a replacement for a pre-existing antibiotic that has not yet succumbed to resistance. ${ }^{173}$ The MIPFA acknowledged the public health benefit from holding antibiotics in reserve. ${ }^{174}$

Therefore, a better fit for the UADS program is a flexible system that confers some level of discretion to administrators in determining the size of the prize. ${ }^{175}$ Such a system allows administrators to correct for various inequities that may result from application of a strictly proportional system, such as inadequate reward for antibiotics that have limited demand or are held in reserve. ${ }^{176}$ Developers of the MIPFA have described one embodiment of this system in which a fraction of the prize (e.g., half) is awarded in proportion to health impact of the drug and the remainder is distributed equally among registrants. ${ }^{177}$ Their hypothetical example illustrates how developers of drugs affecting smaller populations would have incentive to bring such drugs to market under a mixed proportional/discretionary prize distribution system but not under a directly proportional system. ${ }^{178}$

A second, albeit related, consideration in distributing prizes under the UADS model is the timing of payments. As mentioned supra, developers of new drugs under the MIPFA would receive annual payments for up to ten years. ${ }^{179}$ The payment over an extended period allows for a more accurate assessment of the health impact of a new drug. ${ }^{180}$ A similar payment scheme would be appropriate for the UADS model, although a ten-year window may still be too brief to

\footnotetext{
${ }^{172}$ Hollis \& POGGE, supra note 118, at 13-35.

${ }^{173}$ The UADS would have a measure akin to the stockpiling procedure of Project BioShield, see 42 U.S.C.A. $\S$ $247 \mathrm{~d}-6 \mathrm{~b}$, or the strategic antibiotic reserve of the Antibiotic Continued Effectiveness model, see Kesselheim \& Outterson, supra note 4, at 160-61.

${ }^{174}$ See Medical Innovation Prize Fund Act, S. 1137, 112th Cong. § 9(c)(6) (2011).

${ }^{175}$ See Love \& Hubbard, supra note 153, at 1537-39.

${ }^{176} \mathrm{Id}$.

${ }^{177} \mathrm{Id}$.

${ }^{178} \mathrm{Id}$

${ }^{179}$ Medical Innovation Prize Fund Act, S. 1137, 112th Cong. § 9(d)(3) (2011).

${ }^{180}$ Love \& Hubbard, supra note 153, at 1539.
} 
gauge the value of a new antibiotic. However, protracting the payment period in the hope of discerning the health impact of certain antibiotics, i.e., those held in reserve, may be impractical. Thus, the UADS model cannot rely on the timing of payments alone to account for the value of antibiotics held in reserve.

A third consideration in distributing prizes is how to apportion value, and therefore prize money, between first-in-class antibiotics and follow-on derivatives. According to some commentators, one of the fundamental problems of the current patent system is that it encourages development of follow-on drugs over fundamentally new medicines. ${ }^{181}$ A follow-on drug with superior clinical properties to the pioneering drug typically requires much less investment in research and development, and has the potential to usurp the market from the first product. ${ }^{182}$ Thus, follow-on drugs are attractive from the market perspective, but they typically provide only a marginal medical benefit. The reward systems in both the HIF and the MIPFA were specifically designed to correct this misalignment of incentives between private developers and public health. ${ }^{183}$ The possibility of antimicrobial resistance, however, makes antibiotics different from other drugs: a follow-on antibiotic can still have significant therapeutic value as long as it is not susceptible to the same mechanism of resistance that thwarted the effectiveness of the firstin-class drug. In recognition of this issue, the MIPFA required that the "expected life cycle benefits" of a new antibiotic be taken into account when determining the size of the reward. ${ }^{184}$

\section{Features of Phase Two}

\section{Production and sales options.}

The emphasis of phase two of the UADS model is on the public health goal of preserving an effective antibiotic supply. In contrast to the HIF and MIPFA, which seek to improve access to new medicines, the UADS model strives to constrain access to antibiotics to curb

\footnotetext{
${ }^{181}$ Hollis \& POGGE, supra note 118 , at 4.

${ }^{182}$ Love \& Hubbard, supra note 153, at 1542.

${ }^{183}$ See Hollis \& Pogge, supra note 118, at 4; Medical Innovation Prize Fund Act, S. 1137, 112th Cong. § 2 (2011).

${ }^{184}$ Medical Innovation Prize Fund Act, S. 1137, 112th Cong. § 9(c)(6) (2011).
} 
inappropriate uses. Because antibiotics are a common pool resource, regulation of their production and use is necessary to ensure that the resource is available for future generations. ${ }^{185}$ Although patent-based mechanisms for conservation of antibiotics have been proposed, these models do not resolve the fundamental tension between the incentive to conserve an antibiotic and the motivation to sell it to maximize profit. Thus, the UADS model places the responsibility for regulating antibiotic production and sales into the hands of the government.

\section{Direct distribution by government.}

One mechanism for government regulation of antibiotic manufacture and sales is to charge the government with these responsibilities directly. Although this option assures governmental control of antibiotic supply, it has several disadvantages. First, it requires the creation of substantial new governmental bodies that make, test, and distribute drugs. Not only does this increase the cost of the program, it raises questions about the government's experience and expertise in an area in which the private sector excels. ${ }^{186}$ Second, transferring antibiotic production and sales to government bodies would have an immediate adverse impact on companies that currently engage in these activities. The legislative and administrative changes required to implement such a system would therefore likely meet strong opposition by the pharmaceutical industry.

\section{License to drug manufacturers.}

A more moderate approach to regulate antibiotic manufacture and sales is for the government to grant licenses to drug companies. Whereas previously-proposed patent prize systems seek to buy private patent rights to place the inventions (i.e., drugs) in the public domain, here the government exercises its patent rights as would a private patent holder. In this system, the government could issue a revocable license to produce and sell a new antibiotic and

${ }^{185}$ For discussion of antibiotics as a common pool resource, see, LAXMINARAYAN \& MALANI, supra note 160; Kades, supra note 24; Outterson et al., supra note 33, at 562; Kevin Outterson, The Vanishing Public Domain: Antibiotic Resistance, Pharmaceutical Innovation and Intellectual Property Law, 67 U. Pitt. L. Rev. 67, 78-80 (2005).

${ }^{186}$ Power, supra note 46, at 30. 
make the license contingent on meeting certain regulatory requirements. A licensing system takes advantage of the efficiency and experience of drug producers and does not require the establishment of an entirely new governmental workforce. The legislative and administrative changes needed to implement a licensing system would be less drastic than those required for a direct-distribution system. Moreover, the pharmaceutical industry would be more favorably inclined toward such a system for a few reasons. First, a bill proposing such a system would have little impact on this sector because few companies currently engage in antibiotic development. Second, the possibility of licensing antibiotics from the government for manufacture would create future business opportunities for this sector.

\section{Reimbursement.}

A complementary mechanism of phase two of the UADS model is the use of reimbursement by public payers to regulate antibiotic use. The Antibiotic Continued Effectiveness (ACE) Program proposed by one group of commentators recommends using reimbursement to control antibiotic use in two ways: increasing payments to provide a stronger incentive for private drug developers who retain patent rights, and making these payments conditional on meeting conservation goals to promote antibiotic stewardship. ${ }^{187}$ Although these policy levers would operate differently in the absence of private patent rights, they are still applicable in the UADS model. The critical point is that public reimbursement for antibiotics is well below the social value that these drugs provide, so raising payment levels is still efficient if it can achieve some other public health goal. ${ }^{188}$ In the UADS model, public payers such as Medicare and Medicaid would substantially reimburse providers for acceptable uses of antibiotics but not at all for inappropriate uses. The combination of high prices and selective reimbursement discourages low-value uses of antibiotics, such as prescriptions for undiagnosed

\footnotetext{
${ }^{187}$ Kesselheim \& Outterson, supra note 3, at 150-57.

${ }^{188}$ Id. at $151-52$.
} 
infections that are likely to be viral rather than bacterial. ${ }^{189}$ In contrast to the ACE Program, which allows higher antibiotic prices to incentivize development of new antibiotics, the UADS model employs them to deter undesirable uses. Thus, the UADS model uses a licensing system to regulate antibiotic supply and reimbursement to control antibiotic demand.

\section{Antibiotic stewardship.}

A third feature of phase two of the UADS model is the requirement of a government body to oversee antibiotic stewardship. The Strategies to Address Antimicrobial Resistance (STAAR) Act, a bill proposed by Representative Jim Matheson in 2009, provides for the establishment of an administrative body to perform this function. ${ }^{190}$ The STAAR Act calls for the creation of an Antimicrobial Resistance Office (ARO) within the Department of Health and Human Services. ${ }^{191}$ Under the STAAR Act, the ARO would seek guidance from a Public Health Antimicrobial Advisory Board (PHAAB) made up of infectious diseases and public health experts. ${ }^{192}$ The STAAR Act charges these groups with monitoring antibiotic supply through the collection of data on antibiotic use and surveillance of antibiotic resistance. ${ }^{193}$ Although not part of the 2009 STAAR Act, another duty that the ARO could assume is the establishment of a strategic antibiotic reserve (SAR). Creation of a SAR has been described previously as a component of Project Bioshield and the ACE program. ${ }^{194}$ The SAR would include a supply of broad-spectrum or high-potency antibiotics to be used only when front-line antibiotics have lost their effectiveness. ${ }^{195}$

\section{SuPPlEMENTAL MEChaniSMS COMPATIBLE WITH UADS MODEL}

Although the core features of the UADS model are described in Parts III.A to III.C,

\footnotetext{
${ }^{189}$ By one estimate, half of all antibiotic prescriptions for non-hospitalized patients are for infections caused by viruses rather than bacteria. AMERICAN COLLEGE OF PHYSICIANS, Antibiotic Resistance, http://www.acponline.org/patients_families/diseases_conditions/antibiotic_resistance/ (last visited March 17, 2011).

${ }_{190}$ Strategies to Address Antimicrobial Resistance Act, H.R. 2400, 111th Cong. (2009).

${ }^{191} I d . \S 3(\mathrm{a})$.

${ }^{192} \mathrm{Id}$.

${ }^{193} I d . \quad \S \S 4-5$.

${ }^{194} 42$ U.S.C. $\$ 247 d-6 b$; Kesselheim \& Outterson, supra note 4, at 160-61.

${ }^{195}$ See Kesselheim \& Outterson, supra note 4, at 160-61.
} 
implementation of the UADS model does not preclude adoption of other measures to promote antibiotic development and conservation. The patent buyout in phase one of the UADS model is a pull incentive. Many commentators, however, advocate models that incorporate both push and pull incentives to promote drug development. ${ }^{196}$ Several of the push incentives discussed in Part II can be implemented in conjunction with the UADS model because they operate upstream in the development process. Regulatory mechanisms such as tax credits, expedited review, and a streamlined review process can work in concert with the patent buyout in phase one to promote antibiotic development. Some contractual arrangements, e.g., direct funding of research and early-stage research collaborations, would also facilitate antibiotic development in phase one of the UADS model. Thus, the combination of the UADS patent prize with one or more push incentives could produce a more balanced and effective system to stimulate antibiotic innovation.

\section{Conclusion}

Leaders in the medical, scientific, business, and pharmaceutical communities have recognized the need to act to ensure the continued supply of effective antibiotics. Antibiotics are vital to modern medicine, but they may become extinct if current trends in drug development and sales continue. One problem is that the patent system provides an inadequate incentive for the development of new antibiotics because they are less profitable than other drugs. This predicament has stirred much discussion in the context of medicines for neglected diseases, and analysts have proposed a variety of solutions that entail changes to the current patent system. A second problem, which the patent system cannot solve, is that antibiotics eventually lose their effectiveness due to resistance. This challenge requires a public commitment to conservation. As one group of commentators puts it, the crux of the growing antibiotic crisis is that "[p]ublic

\footnotetext{
${ }^{196}$ Morel \& Mossialos, supra note 7, at 1117; Sharma \& Towse, supra note 17 , at 5.
} 
health goals and the goals of the private actors - primarily pharmaceutical manufacturers-are woefully misaligned."197

The UADS model described here would resolve the tension between the public health goals and private interests. The UADS model uncouples the public health goals of antibiotic development and antibiotic conservation so that they are no longer in conflict. Phase one of the UADS model provides incentive to biotechnology and pharmaceutical companies to develop new antibiotics, as they have done successfully in the past when the reward was sufficiently large. The prize awarded to developers of new antibiotics removes the incentive on these private actors to engage in activity contrary to public health goals. Phase two of the UADS model allows both drug companies and the government to fulfill their respective missions: for the companies, making and selling antibiotics as efficiently as possible; and for the government, regulating distribution of antibiotics to balance current and future medical needs. Additionally, by using a licensing system in phase two, the UADS model requires minimal infrastructural change in the government. The UADS model eliminates the institutional conflicts inherent in the current patent system yet has the flexibility to accommodate other mechanisms that promote antibiotic development and conservation. By re-aligning private incentives with public health goals, the UADS model will allow future generations to enjoy the myriad health benefits that antibiotics have let many of us take for granted.

\footnotetext{
${ }^{197}$ Kesselheim \& Outterson, supra note 4, at 167.
} 